\title{
The synthesis: An innovative approach to student research
}

\section{Matthew Molineux}

Background: Although there is an expectation for health practitioners to be able to use research to inform their practice, opportunities for students to actually plan, conduct and report a research project are diminishing. Students are less able to gain first-hand experience of research as a result of demands to include more in curricula, and increasingly rigorous and time-consuming ethical review procedures. It is important, therefore, for health educators to explore different research methods and approaches. Content: This article proposes the synthesis, an entirely literature-based approach, as a method to enable students to plan and conduct a research project. It is more than a literature review in that it requires students to synthesize material from two previously unrelated fields. As a result it is possible to shine a new light on issues facing health-care professionals and their patients/clients, by bringing new ways of thinking to issues.

Conclusions: Although the synthesis is a nascent concept in student health professional education, it has the potential to offer students first-hand experience of the research process, and so contribute to their development as research aware professionals.

Key words: $\mathbf{\text { students }}$ research literature-based

Submitted 17 February 2009, sent back for revisions 16 March; accepted for publication with minor revisions following doubleblind peer review 3 July 2009

$\mathrm{E}$ vidence-based practice is now a well embedded feature of professional practice. All health professionals are expected to be able to source, critique and apply research to their practice. Furthermore an increasing number of professionals are being expected to carry out work-based research projects or audits. Although there may still be debate about the extent to which student health professionals need to be able to design, perform and disseminate research, at the very least the professionals of the future must be research aware. This research imperative may, however, be at odds with the increasingly regulated environment in which research is usually conducted. In the United Kingdom (UK), for example, some universities have decided to not allow students to perform primary research in clinical settings as a result of changes to research governance in the National Health Service. Given this context it is worth considering a wide range of learning experiences that might provide students with the skills and knowledge to be research aware professionals, and at least a rudimentary experience of the research process.

The aim of this article is to provide an overview of one possible alternative to a traditional research project. The 'synthesis' is a method that is informed by 'literature-based discovery', which although not common, is potentially valuable in health education. This article will begin by briefly presenting the context for the development of the synthesis as a research project. Further details about a synthesis will be outlined, including the stages involved and issues to consider, and examples of successful student completed syntheses will be presented.

\section{THE CONTEXT OF STUDENT RESEARCH}

Evidence-based practice is a feature of modern practice for all health professionals. Although the pressure for research to support practice emerged in medicine, it is now an imperative for all health professionals. For example, in the UK, medical practitioners are required by the General Medical Council (2006: p8) to 'provide effective treatments based on the best available evidence'. Similarly, the Health Professions Council (2007) requires all registrants to be able to use research to provide effective services. To prepare students to work in an evidence-based 
manner, educational programmes have in the past included subjects on research methods and, for honours and masters courses, usually required students to design, conduct and report a research project.

\section{Concerns around student research}

The wisdom of requiring students to complete their own research project has been questioned in the last decade. Kitchen (1999) raised several concerns such as the pressure on clinicians to support student research projects by providing access to participants (who might be staff or patients), the impact participating in a research project may have on patient care, and the impact that both of these might have on other studies being performed by more experienced researchers. Other concerns raised include the often mismatched time frames of a student project and those of external ethics committees, the ethics of permitting students as novice researchers to have access to patients, and the questionable quality of small, resource-limited student research (Rouse and Lynam, 2003).

In the UK the pressure to rethink undergraduate/ entry level student research projects was increased with the publication of the Department of Health's (2001a) Research Governance Framework for Health and Social Care. As a result of that document the scope and role of research ethics committees were reviewed, and it was made clear that even if research was being conducted by a student primarily for educational purposes, it would be subject to the same ethical standards as any other research (Department of Health, 2001b). Few would argue of course that exposing research participants to procedures or interventions that are not necessary should be subjected to independent scrutiny; the purpose of the research activity is largely irrelevant. These expectations did, however, raise the stakes for undergraduate/entry level students and their supervisors as the quality of research proposals had to increase to stand up to this greater scrutiny.

\section{Methods of providing student research experiences}

Although the examples above are specific to the UK, it seems that around the world health educators have been reflecting on how to provide student research experiences. Whelan et al (2007) proposed a collaborative approach in which students, academic and clinical staff work on shared projects. This seems a useful method to ensure that students gain first-hand experience of research, that academic staff have time to conduct research, and that clinical staff can use their expertise to inform the research agenda. In the allied health professions this is a model worth considering further, but it relies on academic/clinical staff having projects which students can participate in, and this is not always the case. A number of other alternatives have been proposed in the literature, including voluntary student research groups, conducting research with university students as participants, classroom-based activities to simulate research activities, systematic reviews, critical reviews, document analysis, observational studies, and product evaluation (Kitchen, 1999; Brown, 2002; Hakan et al, 2002; Rouse and Lynam, 2003).

These proposals are all worth further consideration, but may have their own problems. For example, if students begin using other students as participants it will not be long before the student body is overwhelmed with requests to participate in research projects. Also classroom-based simulations are unlikely to enable students to engage in the entire research process, from initial idea and planning through to implementation and reporting. While extended literature reviews or systematic/narrative analyses might be useful in developing some of the skills needed by student health professionals, these methods rarely give students the chance to develop a new insight into an issue. This is because they do not necessarily require students to move beyond discussion and critique to production, creation or innovation. Nonetheless these are all valuable methods for educators to have at their disposal, but some will not be possible within particular contexts and some may be less appropriate in particular professional frameworks. It is therefore necessary to explore a wider range of possible research methods and approaches.

\section{SYNTHESIS: A FORM \\ OF LITERATURE-BASED DISCOVERY}

The synthesis is an approach that has been developed and used primarily in occupational therapy education. It is, however, presented here as a method for consideration for use with other student health professionals as an additional way of providing research experience. A synthesis, as defined here, is a form of research project which does not rely on the collection of primary data from participants/subjects, nor does it rely on the existence of a number of research papers addressing the specific research question under consideration. For those reasons it is neither a traditional project involving primary data collection, a systematic review/meta-analysis nor even a narrative synthesis. A synthesis is more akin to the process of literature-based discovery (Weeber et al, 2001). Two approaches to literature-based discovery have been proposed (Weeber et al, 2001); open and closed.

\section{Open and closed discovery}

An open discovery process involves generating a hypothesis when the end point is unknown, for example, how could providing nutritional advice 
enhance physiotherapy practice? This would begin with an exploration of the literature on provision of nutritional advice to people with disease/illness. This might lead to consideration of the benefits and problems of providing nutritional advice to people with disease/illness, and perhaps the health promotion aspects of doing so. This might in turn lead the researcher to consider the importance of nutritional advice for people with rheumatoid arthritis. A possible endpoint might then be the consideration of the potential for incorporating nutritional advice into physiotherapy intervention programmes for clients with rheumatoid arthritis. The time required to conduct an open discovery process may make it inappropriate for the limited time available to undergraduate/entry level students for a research project.

A closed discovery process focuses on testing a hypothesis. As an example, the hypothesis might be that reframing the causes and consequences of bullying from an occupational science perspective will provide new insights into possible anti-bullying interventions. This approach begins with two bodies of knowledge already identified and so would require a critical overview and synthesis of both: bullying and an occupational perspective of humans and health.

\section{Rationale of approach}

Apart from providing a legitimate research experience for undergraduate/entry level students, the novelty of literature-based discovery approaches is that it provides a chance to make links and connections between previously unconnected bodies of knowledge (Swanson, 1990; Weeber et al, 2001). In this way students can demonstrate their ability, at honours level for example, to appreciate that knowledge is uncertain and ambiguous, to critically evaluate arguments, and to communicate ideas (Quality Assurance Agency for Higher Education, 2008). The rationale for exploring bodies of knowledge that are seemingly unrelated is that the divisions which exist between bodies of knowledge are artificial, and do not correspond to lines of 'absolute cleavage in the... phenomena under investigation' (Lovejoy, 1938: p531). It may be the case, therefore, that similar or related issues are addressed in different knowledge areas which, despite their possible links, remain independent of each other (Swanson, 1990). For that reason, when studying a topic in one division of knowledge it could be argued that to achieve a comprehensive understanding of the topic the researcher 'must take into account material lying... in other - often in several other divisions' (Lovejoy, 1938: p536).

\section{Properties of a synthesis}

A synthesis, as the term is used here, is most similar to a closed discovery process for the following reasons:
At least one of the bodies of knowledge is already known, for example, occupational science and occupational therapy

The other body of knowledge may also be known, as student researchers are likely to bring their own disciplinary backgrounds, interests or experiences

The time required to conduct an open discovery process may make it inappropriate for the limited time available to undergraduate/entry level students for a research project

The end product of a closed discovery project may only be a proposed relationship, suggestion of usefulness, or a hypothesis that would all require further examination.

While there have been some methods proposed for conducting a literature-based discovery (see for example Swanson, 1987; Swanson and Smalheiser, 1997), these are relatively complex and require an advanced understanding of databases and very sophisticated literature searching skills, beyond those that would be expected of student health professionals. However, planning and conducting a synthesis is much like any other research project and so needs to follow the same broad steps. Students must have a broad understanding of the literature, then formulate an aim to be achieved or a question to be answered, plan a study including data collection and data analysis, consider trustworthiness, carry out the research according to the plan, and finally report the project (Kielhofner et al, 2006).

\section{Challenges}

The challenge for students, and indeed their research supervisors, is that unlike other research methods, there is no clear process for conducting a synthesis. For example, as there are no guidelines for searching literature which are particular to this method, much relies on the researcher being able to propose potential links between the bodies of literature (Swanson, 1990). For this reason, it would be necessary for students undertaking such a research project to provide a very clear outline of their literature search strategy, and to do so in quite some detail. This provides a good example of why conducting a synthesis can fully test students' skills and knowledge in research. Given the central place of 'the literature' in a synthesis, it is imperative that students use and develop their skills and knowledge to search, read and appraise the literature. This would provide some evidence as to how methodical and comprehensive the search had been, and would be one way of ensuring the trustworthiness of that stage of the research.

\section{The analysis process}

The analysis process in a synthesis is slightly problematic if one hopes to delineate a clear step-bystep process that would be easily repeatable. This 
is because the process of analysis is largely one of reading to understand the literature, and to identify links and arguments (Swanson, 1990). The other aspect of the analysis process is writing about the literature and the possible or suggested links and hypotheses. Writing can, after all, be a manifestation or representation of thinking, analysis and discovery (Richardson and St Pierre, 2005). Here the process appears similar to the writing undertaken in some forms of qualitative analysis in that there is a certain level of craftsmanship that is not easily described (Goodfellow, 1998a; 1998b). Nonetheless it should be possible for students to demonstrate the process of analysis they undertook by 'letting the reader into the process' (Dickie, 2003: p51).

Students may, however, wish to use more structured methods of analysis as described in research texts which would mean that methodological descriptions could more readily adhere to traditional conventions. This might include subjecting the literature being explored to constant comparison, a form of analysis developed within the grounded theory framework (Charmaz, 2005; Strauss and Corbin, 1998). An alternative might involve using structured tables to dissect the literature being considered such as those used in narrative analyses or systematic reviews (Petticrew and Roberts, 2005; Popay et al, 2006; Steultjens et al, 2005).

\section{Common steps}

Although the precise processes employed to conduct a synthesis will vary depending on the topic, the researcher and the exact methods chosen, a number of steps are likely to be common to all, and these are outlined in Figure 1. It is important to remember that the steps presented here are not a substitute for a clearly articulated and defendable research proposal, which must include all aspects of the research process.

\section{ENSURING RIGOUR}

In all research it is important to take steps to make sure the findings are as robust as possible, and as a form of research, the synthesis is no different. Here it is important to recognize that the criteria for judging research are viewed differently depending on the research paradigm. In quantitative research concern is for reliability and validity, and in qualitative research the focus is trustworthiness. While these are given different labels, and therefore may be seen as different criteria, they can actually be reduced to common concerns (Table 1). All research, regardless of paradigm or methods, must demonstrate what steps have been taken to address issues of truth value, applicability, consistency, and neutrality (Guba, 1981; Lincoln and Guba, 1985; Krefting, 1991). Again, although the underlying principles of demonstrating the robust nature of a study are the same across all research methods and paradigms, as there is no clear guide as to how that should manifest in a synthesis, students must understand the fundamental principles to decide what steps should be taken in their synthesis. For that reason, and because experience has shown that some academics question the robustness of the synthesis, this will be reviewed in some depth.

Truth value concerns the extent to which the researcher has uncovered the 'truth' about the issue under investigation, based on the sources used and the context in which the study was undertaken (Krefting, 1991). Of course in all research, regardless of paradigm and methods, it is highly unlikely that one can determine the absolute truth, if in fact there is a 'truth' at all. To improve the credibility of a synthesis, researchers may therefore ask another person to undertake an analysis of a sample of the literature being considered, or document their analysis process in a reflexive research journal. Applicability concerns the extent to which the findings from one

\section{Figure 1. Common steps in conducting a synthesis}

Identify the two areas of interest: one clearly located within the boundaries of professional knowledge/practice, and the other not connected but with some potential value or application.

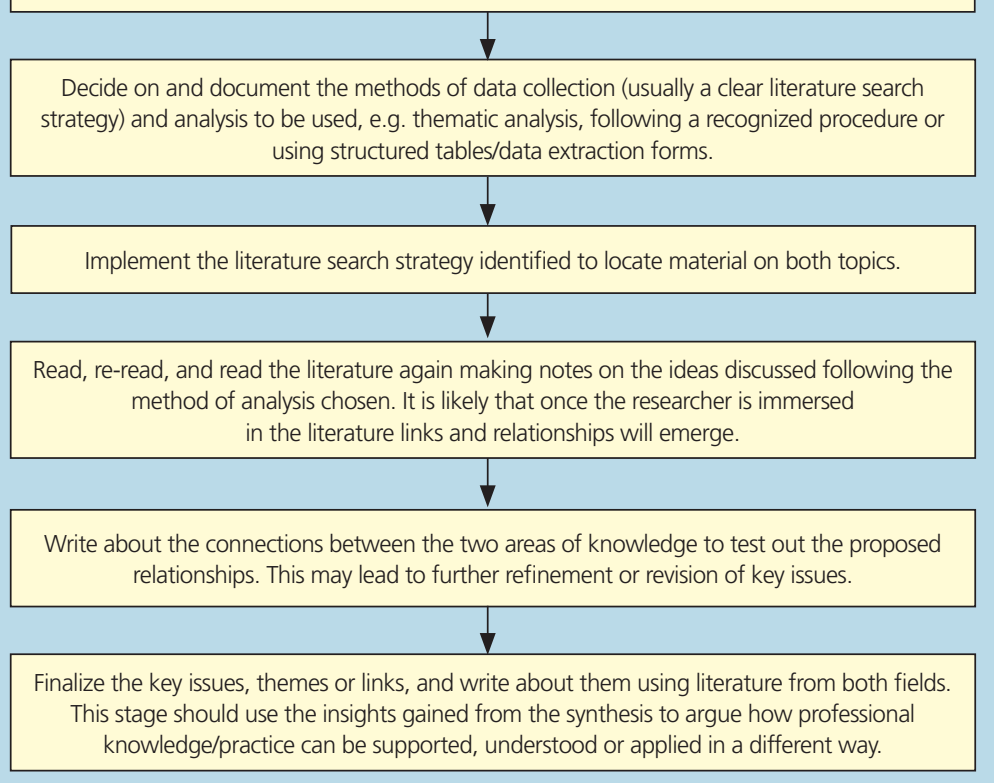

TABLE 1.

Assessing the quality of research (Based on Guba, 1981)

\section{Criterion}

Truth value

Applicability

Consistency

Neutrality

\section{Quantitative}

Internal validity

External validity

Reliability

Objectivity
Qualitative

Credibility Transferabilty

Dependability

Confirmability 
research project can be applied to another group, context, or situation. If generalizability is not a concern for the researcher, this criteria is largely one for the person using that research to satisfy (Lincoln and Guba, 1985). That is, if you want to apply my research to your situation, the responsibility is on you to ensure that it is applicable. That is not to say the researcher can ignore this criteria, as applicability can only be judged if there is sufficient detail provided so that comparisons between situations can be made. It is therefore important for the researcher to provide as clear a description of the research process as possible.

The criterion of consistency focuses on the suggestion that there is likely to be variability within the data gathered and that such variability will be trackable to different sources or analysis methods, for example (Guba, 1981). Here again, peer scrutiny of the analysis and a rich description of the analytical process are useful when reporting a synthesis. Finally, neutrality is the extent to which 'the findings are a function solely of the informants and conditions of the research' and not other factors (Krefting, 1991: p216). To demonstrate this feature a researcher may conduct an audit to document the development of themes that emerge during a synthesis. There are many other examples of strategies researchers can use to maximize the trustworthiness of their research presented in the literature, and some are presented in Table 2.

\section{WHAT DOES A SYNTHESIS LOOK LIKE?}

There are several examples of successful synthesis studies at both undergraduate and postgraduate levels. As part of an honours degree in occupational therapy, Wright (2003) completed a synthesis that explored biophilia as an explanation for the way some humans place great importance on, and derive much satisfaction from, classical horsemanship. Wright approached this project with a strong personal history of involvement with horses as part of her work and leisure, and was interested to explore the theory behind human engagement with the nonhuman environment, but also how that related to theories in her professional field. Biophilia is a theory which explores the way humans are predisposed to

TABLE 2

Strategies to maximize trustworthiness (Adapted from Krefting, 1991)

\begin{tabular}{|c|c|c|c|}
\hline Truth & Applicability & Consistency & Neutrality \\
\hline $\begin{array}{l}\text { - Prolonged exposure } \\
\text { - Reflexivity } \\
\text { - Triangulation } \\
\text { - Peer review }\end{array}$ & $\begin{array}{l}\text { - Dense / 'thick' } \\
\text { description }\end{array}$ & $\begin{array}{l}\text { - Peer examination } \\
\text { - Triangulation } \\
\text { - Dense / 'thick' } \\
\text { description }\end{array}$ & $\begin{array}{l}\text { - Reflexivity } \\
\text { - Confirmability } \\
\text { audit }\end{array}$ \\
\hline
\end{tabular}

have an affinity with other forms of life (Wilson, 1984). Although the human and non-human environments play a significant role in shaping human activity, as understood in occupational therapy, biophilia had not featured in the professional discourse. Wright examined biophilia and classical horsemanship, and professional concepts such as spirituality, object use and wellbeing. She then presented arguments which provided a new insight into professional theories. For example, using insights from biophilia, Wright presented a novel perspective on how humans interact with the non-human environment, and how horsemanship was one way that individuals could develop and master their environment.

Another example of a completed synthesis, at masters level, explored the methods used by actors for character research and their potential utility in occupational therapy (Gregory, 2007). The student who completed this work had a long-standing interest in amateur dramatics and came to realize through her studies that understanding clients in occupational therapy might be complemented by methods from character research. The student carried out her research in a way that would be easily recognizable as a research process, and this was reflected in the presentation of her thesis (see Table 3 for an overview).

Gregory began by providing a rationale for her research and set out aims and objectives. She then completed a review of the two bodies of knowledge she was interested in; acting and character research, and therapeutic relationships in occupational therapy. As outlined above, the methods employed to synthesize the literature are not always easily articulated as it relies on the interpretation of the analyst (Goodfellow, 1998a; 1998b). So while the methodology section is clear it does not provide a step-by-step account of how the final 'themes' were determined. The student included a section on reflexivity and trustworthiness in which she made her interpretative stance explicit and outlined methods used, such as theory triangulation and peer review and discussion. By conducting a synthesis the student was able to make some useful and appropriate links between her two chosen topics, and to the author's knowledge these have not been explored in this way previously. Rather than being completely theoretical, the thesis also included practical techniques that occupational therapists might use to better understand the experiences of their clients.

\section{DISCUSSION}

Although the synthesis is a nascent approach to research, it seems well worth further consideration. Although only two examples were discussed above, several occupational therapy students, at undergrad- 
uate and postgraduate levels, have successfully completed syntheses. Issues that have emerged to date include the need to prepare students sufficiently to conduct a synthesis. There is a risk that students see it as merely a literature review, and so may not be as methodical and rigorous as they should be. It is also necessary to further delineate the methods of literature searching, analysis, and maximizing trustworthiness. While it seems appropriate to use existing methods of data analysis, there are challenges to such an approach when conducting a synthesis. For example, as analysis is largely based on the skill and creativity of the researcher, methods to maximize trustworthiness need to be given careful thought. This challenge is of course common to many methods of qualitative data analysis, and so there may be useful insights in other areas. Nonetheless, further development of the synthesis method would usefully attempt to outline the steps and stages involved, to provide students with practical guidelines. It would also be worth exploring the usefulness of the synthesis in developing research knowledge and skills, as well as the contribution a synthesis can make to professional knowledge and practice.

\section{CONCLUSIONS}

Health educators face challenges in balancing the need to prepare research aware/active professionals of the future with the demands of an increasingly complex research environment. While students should not necessarily be prevented from conducting practice-based research with patients and health professionals, it is important to provide a wide range of possible research options. The synthesis is one method that can be added to the already significant number of innovative methods being used by educators. The synthesis is a literature-based approach to research that although not common in health, is nonetheless legitimate and potentially useful. IJTR

Conflict of interest: none

This article is based on work completed at Leeds Metropolitan University and York St John College. Thank you to all those who shared their views and commented on earlier drafts.

Brown C (2002) Research and undergraduate students: Let's not lose sight of the lightbulb. Occupational Therapy News 10(11): 9

Charmaz K (2005) Grounded theory in the 21st century: Applications for advancing social justice studies. In: Denzin N, Lincoln Y, eds. The Sage Handbook of Qualitative Research/3rd edn. Sage, Thousand Oaks: 507-35

Department of Health (2001a) Research Governance Framework for Health and Social Care. DH, London

Department of Health (2001b) Governance Arrangements for NHS Research Ethics Committees. DH, London

Dickie V (2003) Data analysis in qualitative research: A plea for sharing the magic and the effort. Am J Occup Ther 57(1): 49-56

General Medical Council (2006) Good Medical Practice. GMC, London

Goodfellow J (1998a) Analysing data in narrative inquiry research. In: Higgs J, ed. Writing Qualitative Research.
TABLE 3.

The Occupational Therapist and the Actor (Gregory, 2007) - Thesis outline

Chapter 1 - Introduction

1.1 Introduction

1.2 The structure of the research

1.3 Aims and objectives of the research

Chapter 2 - An actor's character research

2.1 Introduction

2.2 Character development and psychology

2.3 Behaviour and discipline

2.4 Creativity

2.5 A character's behaviour and role

2.6 Character development and language

2.7 Overview

Chapter 3 - Occupational therapy

3.1 Building client awareness and empathy in occupational therapy Introduction

Client-centred and occupation-focused practice

The therapeutic relationship

3.2 Tools and techniques used to encourage client awareness and empathy Reflection

Conceptual practice models

Occupation-based activity analysis

3.3 Overview

\section{Chapter 4 - Methodology}

3.1 Introduction

3.2 Background

3.3 The synthesis approach

3.4 Data sources, collection and analysis

3.5 Reflexivity and trustworthiness

3.6 Overview

\section{Chapter 5 - Synthesising the research}

5.1 Introduction

5.2 Developing the tools and techniques used to encourage client awareness and empathy

Skills to aid reflection

The client's narrative

Developing conceptual practice models

5.3 Building the occupational therapist's skills

Self-discipline and self-awareness

Language and communication

5.4 Overview

$$
\text { Creativity }
$$

\section{Chapter 6 - Discussion}

3.1 Introduction

3.2 Implications for education

3.3 Implications for practice

3.4 Implications for research

3.5 Limitations of the research

3.6 Conclusion

Hampden Press, Sydney: 105-19

Goodfellow J (1998b) Constructing a narrative. In: Higgs J,

ed. Writing Qualitative Research. Hampden Press, Sydney: $175-87$

Gregory P (2007) The Occupational Therapist and the Actor.

Unpublished MSc Occupational Therapy (Pre-registration)

Thesis, Leeds Metropolitan University, Leeds

Guba E (1981) Criteria for assessing the trustworthiness of naturalistic inquiries. Educational Communication and Technology Journal 29: 75-91

Hakan Aydin H, Celik H, Ersoz B (2002) Voluntary student research groups in biochemical education. Med Educ 36(11): 1091-2

Health Professions Council (2007) Standards of Proficiency:

Occupational Therapists. HPC, London 


\section{KEY POINTS}

Research opportunities for students are diminishing and alternative experiences are being explored.

- The synthesis is one possible alternative to more traditional research experiences that educators should consider when planning research subjects for students.

- A synthesis is entirely literature-based and is likely to shed new light on a topic by bringing a fresh perspective.

- Student experiences of conducting a synthesis should be examined to ascertain the benefits in developing research skills and knowledge.

Kielhofner G, Finlayson M, Taylor R (2006) Organising the components of inquiry together: Planning and implementing a coherent study and research tradition. In: Kielhofner G, ed. Research in Occupational Therapy: Methods of Inquiry for Enhancing Practice. FA Davis, Philadelphia: 420-36

Kitchen S (1999) Are student research projects good for research and practice? Physiother Res Int 4(3): iv-vi

Krefting L (1991) Rigor in qualitative research: The assessment of trustworthiness. Am J Occup Ther 45(3): 214-22

Lincoln Y, Guba E (1985) Naturalistic Inquiry. Sage, Beverly Hills

Lovejoy A (1938) The historiography of ideas. Proc Am Philos Soc 78(4): 529-43

Petticrew M, Roberts H (2005) Systematic Reviews in the Social Sciences: A Practical Guide. Blackwell, Oxford

Popay J, Roberts H, Sowden A et al (2006) Guidance on the
Conduct of Narrative Synthesis in Systematic Reviews. Narrative Synthesis in Systematic Reviews, Lancaster

Quality Assurance Agency for Higher Education (2008) The Framework for Higher Education Qualifications in England, Wales and Northern Ireland. QAA, Gloucester

Richardson L, St Pierre E (2005) Writing: A method of inquiry. In: Denzin N, Lincoln Y, eds. The Sage Handbook of Qualitative Research. 3rd edn. Sage, Thousand Oaks: 959-78

Rouse S, Lynam C (2003) Governance of undergraduate student research [Letter]. Physiotherapy 89(1): 69-70

Steultjens E, Dekker J, Bouter L, Leemrijse C, van den Ende C (2005) Evidence of the efficacy of occupational therapy in different conditions: an overview of systematic reviews. Clin Rehabil 19(3): 247-54

Strauss A, Corbin J (1998) Basics of Qualitative Research: Techniques and Procedures for Developing Grounded Theory. 2nd edn. Sage, London

Swanson D (1987) Two medical literatures that are logically but not bibliographically connected. J Am Soc Inf Sci 38(4): 228-33

Swanson D (1990) Medical literature as a potential source of new knowledge. Bull Med Libr Assoc 78(1): 29-37

Swanson D, Smalheiser N (1997) An interactive system for finding complementary literatures: A stimulus to scientific discovery. Artificial Intelligence 91 (2): 183-203

Weeber M, Klein H, de Jong-van den Berg L (2001) Using concepts in literature-based discovery: Simulating Swanson's Raynaud-fish oil and migraine-magnesium discoveries. J Am Soc Inf Sci Technol 52(7): 548-57

Whelan K, Thomas J, Madden A (2007) Student research projects: The experiences of student dietitians, university faculty members, and collaborators. $J$ Am Diet Assoc 107(9): 1567-74

Wilson E (1984) Biophilia: The Human Bond with Other Species. Harvard University Press, London

Wright N (2003) Classical Horsemanship: An Occupation Legitimising Access to the Non-human Environment. Unpublished BSc (Hons) Occupational Therapy Thesis, York St John College, York

\section{COMMENTARIES}

As academics we acknowledge the increased pressure on higher education institutions (HEls) to produce graduates who not only successfully attain an honours degree, but who are fit for practice as allied health professionals (AHP) (Health Professions Council, 2004; 2007). This has required a careful balancing act between meeting the needs of the educational organization and those of the specific professional groups within a very tight timeframe of 3 or 4 years (depending on the institution). This has meant that research material in the undergraduate curriculum is often restricted to one module in a semester (15 weeks), unless the HEl has managed to spread the module across a number of semesters. As the author rightly identifies, time to deliver the research curriculum is further pressurized with the introduction of research governance
(Department of Health, 2001) and ethics procedures now being required in the NHS in the UK, which are time-consuming and often onerous, and subsequently can take longer than the semester to acquire.

Despite these constraints there is the requirement to ensure equality between our AHP degree programmes and other non-AHP degrees elsewhere in the HEls; and to demonstrate to our professional bodies and potential AHP employers that our graduates can demonstrate both awareness and a certain level of research skill. This has become increasingly important as AHPs are required to provide evidence to support the various treatment approaches and interventions they use in practice (Savin-Baden and Fischer, 2005).

Having supervised students who have completed both empirical research and systematic literature reviews it is interesting to reflect on this experience. It surprised me to realize that of those 'pre-research governance' undergraduate students, few have gone on to undertake any further primary research activity, or have had their findings published. This raises an interesting point for me when it is widely perceived that this is the preferred student experience to best support our professions in being more research active, and perhaps illustrates why there continues to be significant knowledge gaps regarding evidence-based practice and research use in some of the allied health professions (Brown and Rodger, 1999a; 1999b; Dobbins et al, 1998; McCluskey and Cusick, 2002).

In contrast, the systematic reviews bring different challenges. While being an easier project to facilitate in the HEls, every effort is required to ensure that they are as systematic and rigorous as possible. Secondly there must be a body of primary research available on a particular topic for the student to critically review, or the student may need to start over and explore another client population or intervention. Thirdly it is vital that the supervisor is familiar with the student's chosen topic as occasionally some students will misinterpret some of the findings. This is important to monitor if students are then going to present their findings at any stage so that the audience receives accurate information, as they may not always go back and read the original paper for themselves. A further difficulty in relying on this model to teach research skills, is that some areas of clinical practice remain underresearched and there is simply not the literature available to be critically reviewed. Additionally, unless the student is able to 
interpret real meaning for clinical practice this type of project does not often contribute further to the existing body of knowledge.

The author presents a potentially useful model which could overcome this latter difficulty, by combining the skills used in completing a systematic critical review, and those of novel enquiry by exploring the combination of two previously unrelated fields. This model offers students the opportunity to draw on personal preferences, to demonstrate the various key research skills, and to contribute to the professional body of knowledge. The opportunity to explore a field of interest should also serve to motivate students to engage with the whole research process, and to make it more meaningful to them.

While the author refers to the academic debate around the validity of this type of research, the skills developed in such a research project reflect those often called on in clinical practice. Many AHPs have become accustomed to drawing on research findings from various other disciplines (for example, education, medicine, ergonomics, and movement science) and applying them to their own field to make evidence-based decisions about their interventions. Therefore this 'synthesis' model would appear to provide the student with the required skills to critically appraise the literature and determine its relevance to their profession's practice. These skills are essential for today's graduates to demonstrate effectiveness of interventions in the evidence-based practice climates in which they will work.

I would, however, suggest some caution in adopting this model, and stress the importance of ensuring that there is adequate time allocated in the curriculum for the student to learn the skills of critical appraisal; to understand what is required in any primary research to ensure it is valid, reliable, trustworthy, or credible; and to rigorously review two previously discrete and unrelated areas, interpreting the connectivity and relevance to clinical practice. I look forward to further discussion on the intricacies of adopting this synthesis model and whether indeed it will foster confidence and competence in future graduates to use and undertake research and thereby continue to drive forward clinical practice.

\section{Jackie Casey}

Course Director \& Lecturer

University of Ulster,

Northern Ireland
Brown GT, Rodger S (1999a) Research utilization models: Frameworks for implementing evidence-based occupational therapy practice. Occup Ther Int 6: 1-23

Brown GT, Rodger S (1999b) Research utilization strategies for occupational therapy practitioners. The Israel Journal of Occupational Therapy 8(4): 105-94

Department of Health (2001) Research Governance Framework for Health and Social Care. DH, London

Dobbins M, Ciliska D, DiCenso A (1998) Dissemination and use of research evidence for policy and practice: A framework for developing, implementing and evaluating strategies. Canadian Nurses Association, Ottawa

Health Professions Council (2004) Standards of Education and Training: Occupational Therapists. HPC, London

Health Professions Council (2007) Standards of Proficiency: Occupational Therapists. HPC, London

McCluskey A, Cusick A (2002) Strategies for introducing evidence-based practice and changing clinician behaviour: A manager's toolbox. Aust Occup Ther J 49(2): 63-70

Savin-Baden M, Fisher A (2005) How effective are student research projects in equipping evidence-based practitioners? LTSN centre for Health Sciences and Practice, Coventry University, UK
Clinicians are required to consistently use evidence, ideally from sound research, in their practice to optimize the safety and quality of the service offered to patients. This supports a need for students to understand the nature, strengths and limitations of research, to be able to make informed and appropriate patient management decisions and consequent actions. On the other hand, logistical challenges and ethical requirements designed to protect the public have made student participation in research activities increasingly difficult.

As the author of this article explains, in response to these challenges, educators have introduced a range of alternative imitative research experiences and/or relevant related activities which do not involve direct data collection from clinical staff or patients. The synthesis approach proposed by the author provides a potentially useful addition to the range of such options already more widely used in undergraduate curricula.

However, a fundamental underlying issue remains, which is perhaps being masked by ongoing pragmatic searches for alternative approaches to enable undergraduate students to complete the research components of their programmes. This is a need-reinforced by both the challenges to research already identified and the educational expectations of clinical practice - to review the nature and extent of research understanding and experience that newly qualified health professionals should demonstrate.

What is the purpose of the research component in honours level qualifications? Do newly qualified clinicians need to be experienced researchers on entry to practice, or do they need to have sufficient insight into research and its impact on evidence-based practice to be able to function as safe, effective practitioners? If the former, then it is perhaps the case that qualification at honours level is insufficient, and students need to undertake qualifying study at masters or doctoral level, as is the case in some professions in some countries. If the latter, then appropriate alternative approaches, which some may currently perceive as compromise in comparison with the historical undertaking of a full clinically-based research project (Palastanga, 1990), would be considered valid activities and experiences. Clinicians with honours qualifications who decide to undertake formal research once they are in practice could then do so, potentially as masters or doctoral degrees, at levels of higher education which have a core research focus.

Justification for such a review is strengthened further by those-cited by the authorwho question the inherent value of student research projects which involve data collection in clinical settings (Rouse and
Lynam, 2003), irrespective of the challenges faced in undertaking such research.

Student research, with its complexities and inherent challenges, is a valid subject to consider in the current context of education and service delivery in the health professions. Whatever the future holds on this issue, this article makes a useful addition to the literature, and highlights the importance of ongoing consideration of the extent and nature of research experience required at qualifying level.

\section{Jenny Morris}

Formerly Lecturer in

Physiotherapy

School of Health Professions and Rehabilitation Sciences,

University of Southampton,

Highfield,

\section{Southampton, UK}

Palastanga N (1990) The case for physiotherapy degrees. Physiotherapy 76: 124- 6

Rouse S, Lyman C (2003) Governance of undergraduate student research [letter]. Physiotherapy 89(1) 69-70 